\title{
MECHANICAL CHARACTERISTICS OF RECYCLED ASPHALT BY SUPERPAVE TECHNIQUE, NAJRAN AREA, KSA.
}

Prof.Dr. M. F. El-Baz* \& Dr. A.K. Abd El Aal**

*Public Works Engineering Dept, Mansoura University, Mansoura.

**Geology Dept., Faculty of Science, Al-Azhar University (Assuit Branch).

\begin{abstract}
ABSTRAC
The physical and mechanical properties of RAP depend on the properties of aggregate, asphalt binder, pavement type, amount of time of the original pavement in service, method of recover in Existing flexible pavements represent available supplies of aggregates that can be recycled. This can significantly contribute to environmental preservation by reducing the amount of new materials required for highway construction and avoiding the problems associated with disposal of the old pavement materials. Recycling also reduces the amount of energy needed to produce the new construction materials and transport those materials to the roadway construction site. Recycling has been defined as "the reuse, usually after some processing, of a material that has already served its first-intended purpose". The recycling procedures in pavement construction have many economical advantages over the traditional procedures.
\end{abstract}

This paper evaluated the performance Superpave mix designs containing recycled asphalt pavement (RAP). The RAP used in each mix design contained aggregate from the same source as the virgin aggregate. The 3-Tier concept was used to incorporate RAP into the mixtures in the first (less than 15\%),15: $25 \%$ and third (greater than 25\%) tiers. Each mix was also made by modifying the respective binder with rubber. In general, the mixtures containing RAP improved the rutting resistance and either increased, or had no significant effect on the indirect tensile strength (ITS). The tensile strength ratio (ITS) was not affected by the addition of RAP.

The recycled asphalt mixture samples were tested in the laboratory. The results indicated that asphalt in the old mixtures used for recycling have low penetration and high softening point. It has also been indicated that asphalts in the recycled mixtures made by the Rejuvenating method have not been rejuvenated completely. The results also showed that Fatigue life of the recycled mixtures is longer than that of the conventional mixture. Other characteristics have been identified such as water-resistance, which showed that the recycled asphalt has high water-resistance.

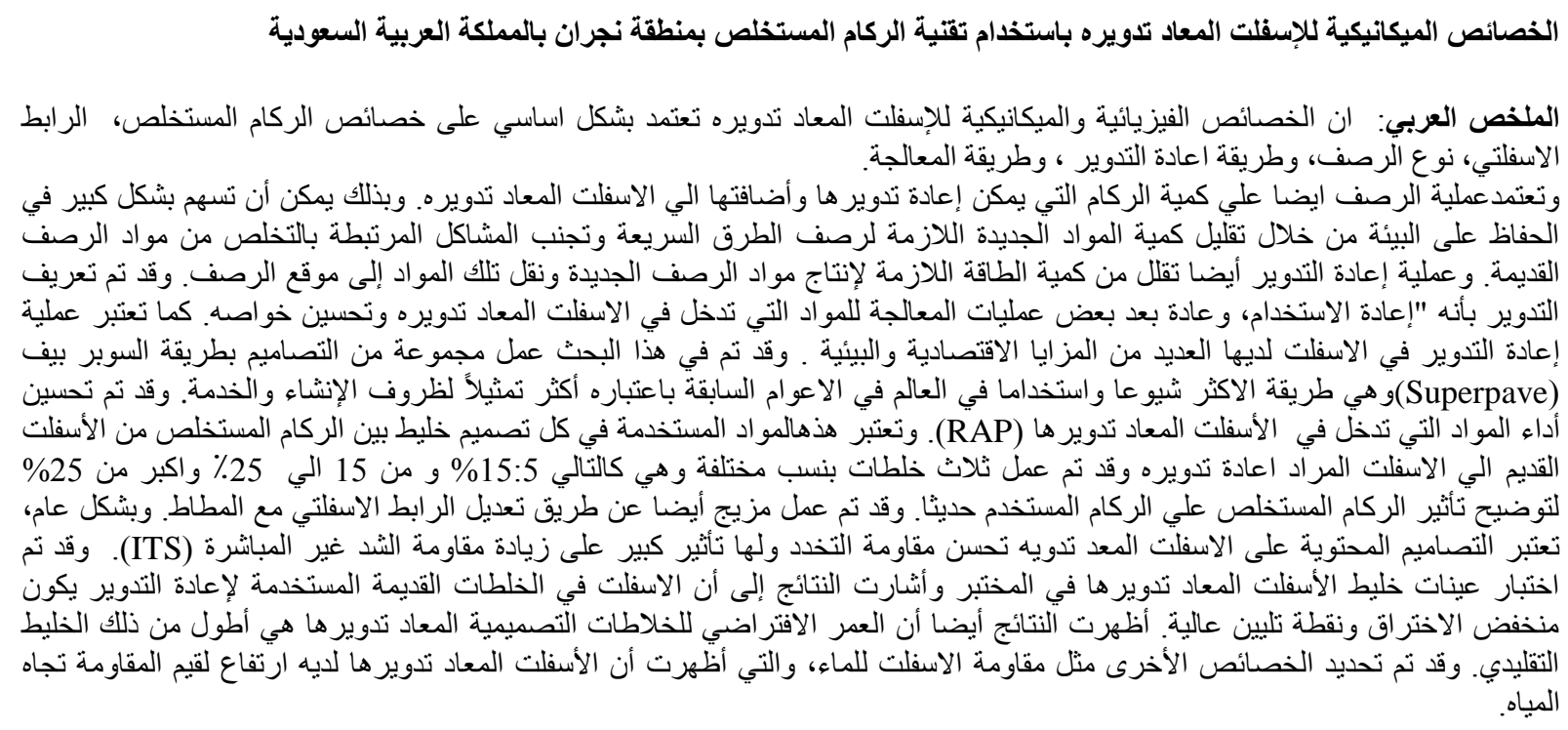

Keywords:Asphalt Recycling, Mechanical Characteristics, Superpave, Asphalt Mixtures

Engineering Research Journal, Vol. 38, No. 4, October 2015, PP: 339-348 


\section{INTRODUCTION}

Pavement recycling is a logical and practical way to conserve our diminishing supply of construction materials and to help reduce the cost of preserving our existing pavement network. When properly designed and constructed, recycled pavements have been found to perform as well as pavements built with all new materials [1,2].

The base and sub-base layers of this foundation are constructed using large volumes of aggregates such as crushed stone, gravel and sand. Because of the high cost of purchasing and transporting aggregate, Najran transportation agencies are interested in replacing a portion of it with recycled construction and industrial materials when constructing new pavements. These materials include asphalt shingle, fly ash, municipal solid waste bottom ash, shredded tires, and concrete or asphalt reclaimed during the reconstruction of existing pavements. Using these materials also benefits the environment by enabling productive use of materials that might otherwise be sent to landfills.

\section{GENERAL CHARACTERISTICS OF (RAP)}

The characteristics of RAP are largely dependent on the characteristics of the constituentmaterials and the type of the asphalt concrete (wearing course, base course) used in old pavements. The aggregates used in the asphalt wearing course and base course have different requirements, such as aggregate quality and size. The aggregate used in the asphalt surface course requires sufficient resistance to abrasion. However, the aggregate in the asphalt base course is not required for abrasion resistance. This difference leads to the use of higher quality aggregate in the surface layer than in the asphalt base layer. The composition of RAP is influenced by several factors, such as the number of pavement resurfacings, the amount of patching and/or crack sealing, possible presence of prior seal coat applications, and percent of asphalt cement used in each maintenance activity.

\section{ASPHALT RECYCLING METHODS}

Hot Mix Recycling is the most common method of recycling asphalt pavements. It involves combining RAP with new or "virgin" aggregate, new asphalt binder, and/or recycling agents* in a central hot mix plant to produce a recycled mix. The amount of RAP allowed in a recycled mix and guidelines as to where the recycled mix can be used in the pavement structure varies by agency. Some agencies routinely allow $15 \%$ or less RAP while others permit larger amounts of RAP. Higher RAP concentrations require adjustments in mix design and binder selection. Suggested guidelines relative to RAP content in a recycled mix are as follows 1) 5: $15 \%$ RAP or less: PG binder is the same as that used in a virgin mix. 2) $15-25 \%$ RAP: PG binder should be one grade lower on both high and low temperature end, i.e. PG 70-10 (Fig.1). 3)>25\% RAP: Test and blend the recovered asphalt from RAP with virgin asphalt as part of the design process to determine the amount of RAP to use. Once RAP has been hauled to a central plant, it is processed and stored for future use. Processing may include crushing and screening the RAP prior to stockpiling. When large quantities of RAP come from different sources, the stockpiles should be separated and identified by source. However, space constraints and limited quantities of RAP from some sources often result in a composite or blended stockpile that needs to be properly characterized. Separating the RAP into different sizes will minimize segregation of RAP particles and allow greater flexibility in adjusting RAP content to meet required final aggregate gradation. Since moisture in RAP can have a major effect on the amount of RAP used or the quality of the recycled mix, it is important for the contractor to monitor RAP moisture and utilize best management practices to minimize moisture.

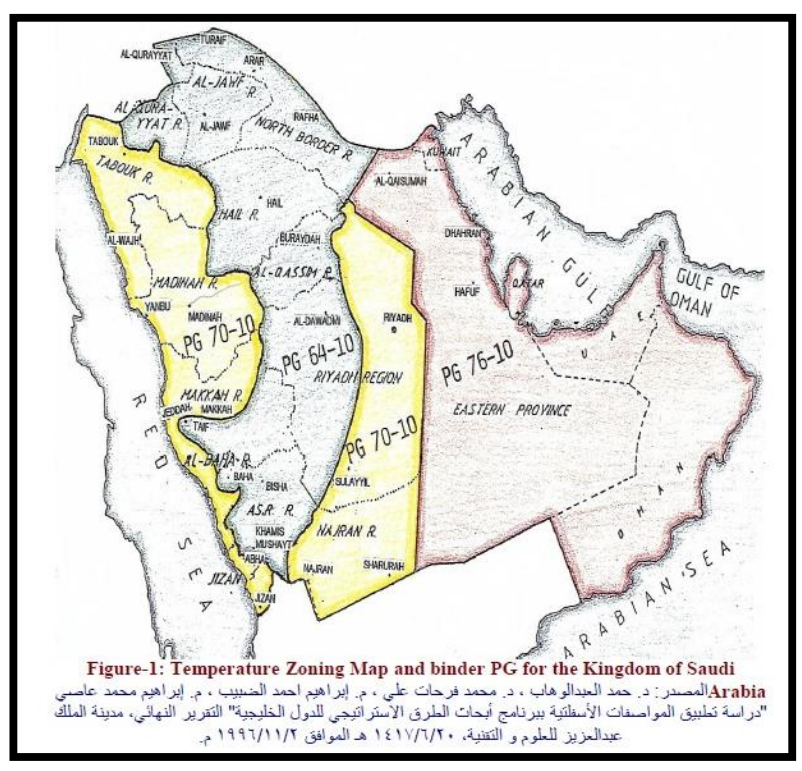

Fig. (1): Temperature zoning map and binder (PG) for the Kingdom of Saudi Arabia [3]

\section{SAMPLING AND MATERIALS}

The amount of sampling and type of testing depends, in large part, on the recycling method selected. The process is straightforward for Hot Mix Recycling where $15 \%$ or less RAP is used. The material from an existing pavement is typically milled and brought to a hot mix asphalt facility where it is crushed, screened, and stockpiled. The contractor then monitors the quality of the RAP to ensure uniformity through gradation and binder testing. Hot Mix Recycling that involves the use of 15-25\% RAP will likely require an adjustment to the virgin asphalt selected (use of a softer grade). For higher than $25 \%$ RAP mixes, a more comprehensive processing, monitoring, and testing 
program for the RAP and the finished recycled mix is needed.

\section{AIM OF THE PRESENT STUDY}

The goal of this study is to compare the suitability of recycled materials to that of virgin aggregates for use in the construction of road base and sub-base layer. We started by collecting recycled materials from various locations in Najran area. Then mix these materials in $15-25 \%$ and combinations with virgin aggregate, creating 11 samples. We evaluated the mechanical and environmental properties of these samples as well as one sample of 100 percent virgin aggregate by measuring:

- Particle size distribution by repeatedly sieving samples and then calculating the ratio of the remaining to original material.

- Optimum water content corresponding to maximum dry density (Gmm)by packing moist samples at various water contents in a gyratory compactor.

- Water retention: to measure the pore size distribution by desaturating the compacted specimens in pressure plate chambers and measuring the amount of water retained in the specimens under various conditions.

- Hydraulic conductivity: which is the rate at which water flows through a material measured at both the point of saturation and a little lower than this during the leaching test.

- Resilient modulus: is a measure of material stiffness by applying cycles of axial stress to cylindrical specimens in a triaxial cell at and slightly below its optimum water content.

- Indirect tensile strength (ITS): to measure of material cohesion by applying a small contact load to a specimen and increasing it until the specimen fails to support it.

\section{ASPHALT MIXTURE SAMPLES (TEST SAMPLES)}

At 11 places on roads in Najran City i, asphalt mixture samples were collected from the surfaces of pavements constructed many years ago. Their surface conditions are all still good but there are slight cracks. Eight of the surface eleven have been constructed using recycled mixtures made by the Rejuvenating Method. Two have been constructed using recycled mixtures made by the Blending Method. The other had been constructed using conventional asphalt mixture made from new materials. The details of Test pavements for the research are shown in table (1). The test samples of asphalt mixtures were cut from the pavements about one year after construction.

\section{STRUCTURALDESIGN CONSIDERATIONS}

Structural design considerations are also important in recycling projects. Recycling and reclaiming processes can be used to correct structural deficiencies in the existing pavement and to address future traffic needs. Knowledge about the strength properties of the various pavement layers allows the designer to use mechanistic-empirical analysis to determine the required overall pavement structure. The strength of the treated layers, including the recycled or reclaimed section, can be determined from stability, resilient modulus, and moisture sensitivity tests.

The annual achievements in recent years have surpassed the planned targets. The proportion of recycled mixtures in the total mixtures used for the year is fast approaching the present target of $50 \%$. The recycled asphalt mixtures are made by too methods. One is by the addition of old mixture into the new [4], which is referred to here as the Blending Method. Another is by use of recycling agents referred to as the rejuvenating Method.

In the Blending Method, old asphalt mixtures are reused together with new asphalt mixture. The old asphalt mixture constitutes less than $40 \%$. The old mixture is not heated directly, but by radiation of hot new material. In the Rejuvenating Method, old asphalt mixture is heated and mixed in a special plant for reuse. Consistency of asphalt is controlled by addition of recycling agents. This paper presents findings of research on mechanical characterization of recycled asphalt mixtures made by the two methods as well as superpave method. The recycled asphalt mixture samples were cut from constructed surfaces in the field and were tested in the laboratory.

\section{DESIGN AND TESTING PROCEDURES}

A $25 \mathrm{~mm}$ Superpave mixture was used for the mix designs in this experiment. This particular mix design is for a primary route surface course mix in South Carolina. $\quad 25 \mathrm{~mm}$ Superpave volumetric and compaction specifications, shown in Table 2, were used [6]. The rut resistance of each mixture was tested using the Asphalt Pavement Analyzer (APA) on the basise of traffic loading, PG grad and temperature zone in the KSA. Six cylindrical APA samples were prepared for each mix design using the Superpave gyratory compactor. The $150 \mathrm{~mm}$ diameter samples were compacted to a height of $75 \mathrm{~mm}$ and prepared to reach $4 \pm 1 \%$ air voids. All samples were conditioned and tested at $64^{\circ} \mathrm{C}$. Each set of samples was conditioned at $64 \mathrm{oC}$ for 4 hours prior to testing in the APA machine. During testing, the test chamber in the APA was maintained at a temperature of $64^{\circ} \mathrm{C}$. The APA settings used were a downward force of $445 \mathrm{~N}$ and the rubber hoses were pressurized to $689 \mathrm{kPa}$ (Tables 2-5). 
Table 1. Test Pavements for the Research Work

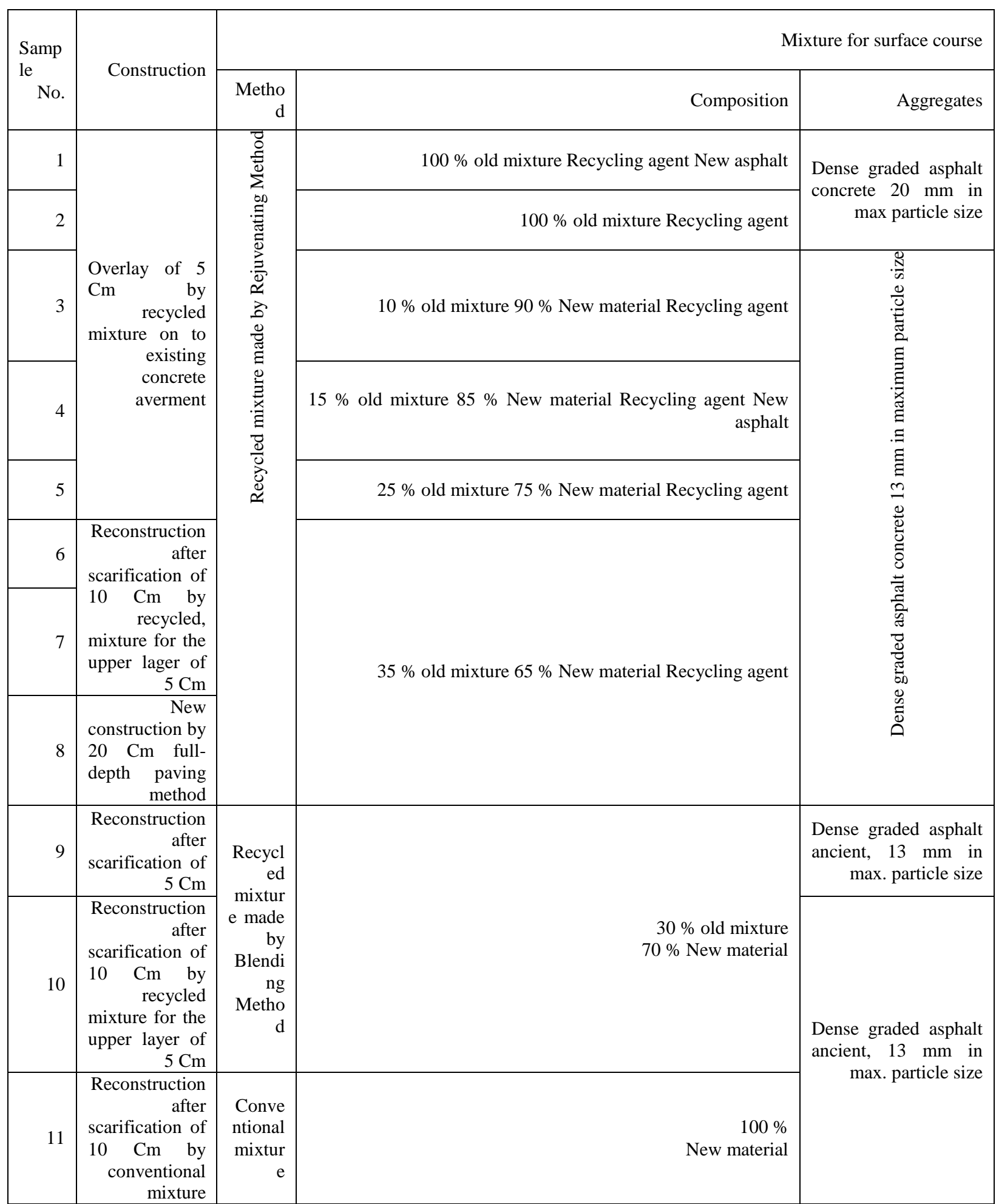


Prof.Dr. M. F. El-Baz\& Dr. A.K. Abd El Aal ' MECHANICAL CHARACTERISTICS OF RE...... “'

Table (2): Selection of design aggregate structure (DAS).

\begin{tabular}{|c|c|c|c|c|c|c|c|}
\hline \multicolumn{8}{|c|}{ Aggregate Gradation } \\
\hline \multirow{3}{*}{$\begin{array}{l}\text { Sieve Size } \\
\text { raised to } \\
0.45 \text { power }\end{array}$} & \multirow{2}{*}{\multicolumn{2}{|c|}{ Sieve Size }} & \multicolumn{5}{|c|}{ Percentage Passing } \\
\hline & & & \multicolumn{5}{|c|}{ Samples From the Hot Bins } \\
\hline & $\mathrm{mm}$ & in & Agg. \#1 & Agg. \# 2 & Agg. \# 3 & Agg. \# 4 & Agg. \#5 \\
\hline 5.81 & 50.0 & 2 & 100.0 & 100.0 & 100.0 & 100.0 & 100.0 \\
\hline 5.11 & 37.5 & 1.5 & 100.0 & 100.0 & 100.0 & 100.0 & 100.0 \\
\hline 4.26 & 25 & 1 & 49.4 & 100.0 & 100.0 & 100.0 & 100.0 \\
\hline 3.76 & 19.0 & $3 / 4$ & 5.4 & 93.7 & 100.0 & 100.0 & 100.0 \\
\hline 3.12 & 12.5 & $1 / 2$ & 0.3 & 15.6 & 98.1 & 100.0 & 100.0 \\
\hline 2.75 & 9.5 & $3 / 8$ & 0.2 & 0.5 & 74.2 & 100.0 & 100.0 \\
\hline 2.02 & 4.75 & No.4 & 0.1 & 0.1 & 27.7 & 99.9 & 100.0 \\
\hline 1.47 & 2.36 & No 8 & 0.1 & 0.1 & 2.7 & 80.3 & 100.0 \\
\hline 1.08 & 1.18 & No 16 & 0.1 & 0.1 & 0.5 & 49.8 & 100.0 \\
\hline 0.79 & 0.60 & № 30 & 0.1 & 0.1 & 0.3 & 26.4 & 99.7 \\
\hline 0.58 & 0.30 & No 50 & 0.1 & 0.1 & 0.2 & 7.9 & 98.5 \\
\hline 0.43 & 0.15 & No 100 & 0.1 & 0.0 & 0.1 & 1.8 & 93.3 \\
\hline 0.31 & 0.075 & No. 200 & 0.0 & 0.0 & 0.1 & 1.2 & 70.7 \\
\hline \multicolumn{8}{|c|}{ Suggested Blending Percentages } \\
\hline \multicolumn{2}{|r|}{ Blend \# } & Total & Agg. \#1 & Agg. \# 2 & Agg. \# 3 & Agg. \# 4 & Agg. \# 5 \\
\hline \multicolumn{2}{|r|}{ Blend 1} & 100.0 & 16.0 & 23.0 & 36.0 & 21.0 & 4.0 \\
\hline \multicolumn{2}{|r|}{ Blend 2} & 100.0 & 12.0 & 12.0 & 43.0 & 26.0 & 7.0 \\
\hline & Blend 3 & 100.0 & 14.0 & 19.0 & 39.0 & 22.0 & 6.0 \\
\hline
\end{tabular}


Prof.Dr. M. F. El-Baz\& Dr. A.K. Abd El Aal " MECHANICAL CHARACTERISTICS OF RE...... .

Table (3): Estimated combined of the blends with superpave criteria.

\section{Estimated Combined Properties of the Blends and Comparison with Superpave Criteria}

\begin{tabular}{|c|c|c|c|c|c|c|}
\hline Property & \multicolumn{2}{|c|}{ SUPERPAVE Criteria } & Blend 1 & Blend 2 & Blend 3 & Remarks \\
\hline Bulk Specific Gravity & $\mathrm{G}_{\mathrm{sb}}$ & n/a & 2.813 & 2.802 & 2.810 & \\
\hline Apparent Specific Gravity & $\mathrm{G}_{\mathrm{sa}}$ & n/a & 2.934 & 2.927 & 2.931 & \\
\hline Water Absorption, \% & Pbw & n/a & 1.509 & 1.611 & 1.545 & \\
\hline \multirow{4}{*}{$\begin{array}{l}\text { Coarse Aggregate Angularity, \% } \\
\text { min. }\end{array}$} & $1+$ Faces & 85 & 96.6 & 96.6 & 96.6 & \\
\hline & \multicolumn{2}{|c|}{ Meet the Criteria? } & Yes & Yes & Yes & \\
\hline & 2+ Faces & 80 & 92.0 & 92.0 & 92.0 & \\
\hline & \multicolumn{2}{|c|}{ Meet the Criteria? } & Yes & Yes & Yes & \\
\hline \multirow{2}{*}{ Fine Aggregate Angularity, \% min. } & FAA & 45 & 46.0 & 46.0 & 46.0 & \\
\hline & \multicolumn{2}{|c|}{ Meet the Criteria? } & Yes & Yes & Yes & \\
\hline \multirow{2}{*}{ Flat \& Elongated, \% max } & F\&E & 10 & 4.6 & 4.6 & 4.6 & \\
\hline & \multicolumn{2}{|c|}{ Meet the Criteria? } & Yes & Yes & Yes & \\
\hline \multirow{2}{*}{ Sand Equivalent, \% min } & SE & 45 & 58.0 & 58.0 & 58.0 & \\
\hline & \multicolumn{2}{|c|}{ Meet the Criteria? } & Yes & Yes & Yes & \\
\hline
\end{tabular}


Prof.Dr. M. F. El-Baz\& Dr. A.K. Abd El Aal ' MECHANICAL CHARACTERISTICS OF RE...... “'

Table (4): Summary of the densification data for the trial blends.

\begin{tabular}{|c|c|c|c|c|c|c|}
\hline & \multicolumn{2}{|c|}{ Blend 1} & \multicolumn{2}{|c|}{ Blend 2} & \multicolumn{2}{|c|}{ Blend 3} \\
\hline Percent of the initial trial asphalt binder, $P_{b i}$ & \multicolumn{2}{|c|}{4.5} & \multicolumn{2}{|c|}{4.5} & \multicolumn{2}{|c|}{4.5} \\
\hline \multirow{2}{*}{ Property } & \multicolumn{6}{|c|}{ Sample No. } \\
\hline & 1 & 2 & 1 & 2 & 1 & 2 \\
\hline Height of samples at $\mathrm{N}_{\text {ini }}$ & 129.5 & 128.3 & 125.1 & 125.6 & 130.8 & 131.3 \\
\hline Average Height of samples at $N_{\text {ini }}$ & \multicolumn{2}{|c|}{128.9} & \multicolumn{2}{|c|}{125.4} & \multicolumn{2}{|c|}{131.1} \\
\hline Height of samples at $\mathrm{N}_{\text {des }}$ & 116.0 & 114.1 & 113.0 & 113.3 & 117.8 & 118.4 \\
\hline Average Height of samples at $\mathrm{N}_{\text {des }}$ & \multicolumn{2}{|c|}{115.1} & \multicolumn{2}{|c|}{113.2} & \multicolumn{2}{|c|}{118.1} \\
\hline Weight of Sample (Oven Dry), g & 5038.9 & 5041.4 & 5052.5 & 5059.3 & 5084.0 & 5090.0 \\
\hline Weight of Sample (Saturated Surface Dry), g & 5068.8 & 5070.6 & 5070.9 & 5090.0 & 5109.5 & 5111.8 \\
\hline Weight of Sample in Water, $\mathrm{g}$ & 3079.3 & 3083.0 & 3054.4 & 3068.2 & 3095.0 & 3096.0 \\
\hline Bulk Specific Gravity $\left(G_{m b}\right) @ N_{\text {des }}$ & 2.533 & 2.536 & 2.506 & 2.502 & 2.524 & 2.525 \\
\hline Average Bulk Specific Gravity $\left(G_{m b}\right) @ N_{\text {des }}$ & \multicolumn{2}{|c|}{2.535} & \multicolumn{2}{|c|}{2.504} & \multicolumn{2}{|c|}{2.524} \\
\hline Wight of the Loose Mix, $\mathrm{g}$ & 2448.0 & 2473.0 & 2471.0 & 2457.0 & 2484.0 & 2493.0 \\
\hline Weight of Flask With Water, g & 10211.0 & 10211.0 & 10211.0 & 10211.0 & 10211.0 & 10211.0 \\
\hline Weight of Flask with Water and Loose Mix, g & 11747.0 & 11761.0 & 11755.0 & 11747.0 & 11766.0 & 11772.0 \\
\hline Maximum Specific Gravity $\left(\mathrm{G}_{\mathrm{mm}}\right)$ & 2.684 & 2.679 & 2.666 & 2.668 & 2.674 & 2.675 \\
\hline Average Maximum Specific Gravity $\left(\mathrm{G}_{\mathrm{mm}}\right)$ & \multicolumn{2}{|c|}{2.682} & \multicolumn{2}{|c|}{2.667} & \multicolumn{2}{|c|}{2.674} \\
\hline \multicolumn{7}{|c|}{ Determination of Volumetric Properties of the Trial Blends } \\
\hline Computed Value & \multicolumn{2}{|c|}{ Blend 1} & \multicolumn{2}{|c|}{ Blend 2} & & \\
\hline$\% \mathrm{G}_{\mathrm{mm}} @ \mathrm{~N}_{\mathrm{ini}}$ & & & & & & \\
\hline$\% \mathrm{G}_{\mathrm{mm}} @ \mathrm{~N}_{\text {des }}$ & & & & & & \\
\hline$\%$ Air Voids & & & & & & \\
\hline$\% \mathrm{VMA}_{\text {ini }}$ & & & & & & \\
\hline Percent of the initial trial asphalt binder, $\mathrm{P}_{\mathrm{bi}}$ & & & & & & \\
\hline Calculated $\mathrm{G}_{\mathrm{se}}$ from $\mathrm{G}_{\mathrm{mm}}$ & & & & & & \\
\hline$\%$ Asphalt Absorption, $\mathrm{P}_{\mathrm{ba}}$ & & & & & & \\
\hline Determination of Volumetric $\mathrm{Pr}$ & opertie & for th & Trial & ends a & $4.0 \%$ & Voids \\
\hline Estimated Values & & & & $\mathrm{d} 2$ & & d 3 \\
\hline Estimated asphalt @ 4.0\% air voids ( $\left.\mathrm{Pb}_{\text {estimated }}\right)$ & & & & & & \\
\hline$\% \mathrm{G}_{\mathrm{mm}} @ \mathrm{~N}_{\mathrm{ini}}$ & & & & & & \\
\hline$\% \mathrm{G}_{\mathrm{mm}} @ \mathrm{~N}_{\text {des }}$ & & & & & & \\
\hline$\%$ Air Voids & & & & & & \\
\hline Voidage Constant (C) & & & & & & \\
\hline$\% \mathrm{VMA}_{\text {estimated }}$ & & & & & & \\
\hline$\%$ VFA estimated $_{1}$ & & & & & & \\
\hline Effective asphalt binder content $\left(\mathrm{P}_{\mathrm{be}}\right)$ & & & & & & \\
\hline Dust Proportion (DP ratio) & & & & & & \\
\hline Comparison of Volumetric & Proper & es of & Trial & lends & ith Cri & ria \\
\hline Computed Value & & & & $\mathrm{d} 2$ & & d 3 \\
\hline$\% \mathrm{G}_{\mathrm{mm}} @ \mathrm{~N}_{\mathrm{ini}}$ & & & & & & \\
\hline$\% \mathrm{G}_{\mathrm{mm}} @ \mathrm{~N}_{\text {des }}$ & & & & & & \\
\hline$\%$ Air Voids & & & & & & \\
\hline$\% \mathrm{VMA}_{\text {estimated }}$ & & & & -ligh & & \\
\hline$\%$ VFA $A_{\text {estimated }}$ & & & & & & \\
\hline Dust Proportion (DP ratio) & & & & & & \\
\hline
\end{tabular}


Prof.Dr. M. F. El-Baz\& Dr. A.K. Abd El Aal ' MECHANICAL CHARACTERISTICS OF RE...... “'

Table (5): Evaluation of strength and moisture sensitivity AASHTO T283.

\begin{tabular}{|c|c|c|c|c|c|c|}
\hline \multicolumn{6}{|c|}{ Required SGCE (No of Gyrations) to Achieve 7.0 Air Voids $(\% \mathrm{Gmm}=93.0 \%)=$} & 42 \\
\hline \multicolumn{7}{|l|}{ Original Samples } \\
\hline \multirow[t]{3}{*}{ Property } & \multicolumn{6}{|l|}{ Sample } \\
\hline & \multicolumn{3}{|c|}{ Dry Set (control) } & \multicolumn{3}{|c|}{ Wet-Set (Conditioned) } \\
\hline & Sample 1 & Sample 2 & Sample 3 & Sample 4 & Sample 5 & Sample 6 \\
\hline Diameter, $\mathrm{mm}$ & 150.0 & 150.00 & 150.00 & 150.00 & 150.00 & 150.00 \\
\hline Thickness, mm & 93.3 & 93.3 & 93.8 & 93.3 & 93.1 & 92.1 \\
\hline $\begin{array}{l}\text { Weight of Dry Sample in } \\
\text { Air, g }\end{array}$ & 3949.5 & 3959.3 & 3948.5 & 3952.2 & 3931.4 & 3939.8 \\
\hline $\begin{array}{l}\text { Weight of SSD Sample } \\
\text { in Air, } g\end{array}$ & 3967.4 & 3975.3 & 3975.0 & 3970.2 & 3953.1 & 3953.2 \\
\hline $\begin{array}{l}\text { Weight of Sample in } \\
\text { Water, } g\end{array}$ & 2372.0 & 2366.1 & 2371.0 & 2365.7 & 2352.4 & 2363.0 \\
\hline Volume & 1595.4 & 1609.2 & 1604.0 & 1604.5 & 1600.7 & 1590.2 \\
\hline Bulk Specific Gravity & 2.476 & 2.460 & 2.462 & 2.463 & 2.456 & 2.478 \\
\hline $\begin{array}{ll}\text { Maximum } & \text { Specific } \\
\text { Gravity }\left(\mathrm{G}_{\mathrm{mm}}\right) & \end{array}$ & 2.646 & 2.646 & 2.646 & 2.646 & 2.646 & 2.646 \\
\hline$\%$ Air Voids & 6.4 & 7.0 & 7.0 & 6.9 & 7.2 & 6.4 \\
\hline Maximum load, Newton & 20372.0 & 20001.0 & 19755.0 & & & \\
\hline $\begin{array}{lll}\text { DRY } & \text { Tensile } & \text { Strength, } \\
\mathrm{kPa} & \end{array}$ & 927 & 910 & 894 & Remarks: & & \\
\hline $\begin{array}{ll}\text { Average DRY } & \text { Tensile } \\
\text { Strength, } \mathrm{kPa} & \end{array}$ & 910 & & & & & \\
\hline \multicolumn{7}{|c|}{ Conditioned 24 Hours in $60^{\circ} \mathrm{C}$ Water } \\
\hline \multicolumn{4}{|l|}{ Thickness, mm } & 92.3 & 93.5 & 93.7 \\
\hline \multicolumn{4}{|l|}{ Maximum Load, Newton } & 16668.0 & 16544.0 & 17038.0 \\
\hline \multicolumn{4}{|l|}{ Wet Tensile Strength, $\mathrm{kPa}$} & 766 & 751 & 772 \\
\hline \multicolumn{7}{|c|}{ Computation and Comparison with SUPERPAVE Criteria } \\
\hline Property & ITS & $\begin{array}{l}\text { Tensile } \\
\text { Ratio (TS }\end{array}$ & Strength & $\begin{array}{l}\text { Meet the } \\
\text { Criteria? }\end{array}$ & $\begin{array}{l}\text { SUPERP } \\
\text { Max. }\end{array}$ & JE Criteria, \% \\
\hline $\begin{array}{l}\text { Tensile Strength of the } \\
\text { Dry set, } \mathrm{kPa}\end{array}$ & 910 & \multirow{2}{*}{\multicolumn{2}{|c|}{$83.8 \%$}} & \multirow[t]{2}{*}{ Yes } & \multirow{2}{*}{\multicolumn{2}{|c|}{$80.0 \%$}} \\
\hline $\begin{array}{l}\text { Tensile Strength of the } \\
\text { Wet set, } \mathrm{kPa}\end{array}$ & 763 & & & & & \\
\hline
\end{tabular}


Table (6): Test Results of Asphalts Recovered from Mixture Samples

\begin{tabular}{|c|c|c|c|c|c|c|c|c|c|c|c|}
\hline Sample no. & 1 & 2 & 3 & 4 & 5 & 6 & 7 & 8 & 9 & 10 & 11 \\
\hline Penetration at $25^{\circ} \mathrm{c}$ & 30 & 30 & 40 & 35 & 34 & 23 & 26 & 27 & 39 & 28 & 30 \\
\hline Softening point $\left({ }^{\circ} \mathrm{c}\right)$ & 60 & 59 & 56 & 56 & 57 & 60 & 59 & 59 & 54 & 57 & 55 \\
\hline Penetration index & -0.22 & -0.31 & -0.34 & -0.64 & -0.54 & -0.61 & -0.57 & -.057 & -0.83 & -0.81 & -0.77 \\
\hline Resins fraction $\%$ & 30.6 & 25.3 & 24.5 & 25.0 & 14.6 & 24.2 & 14.3 & 20.0 & 23.4 & 23.1 & 28.1 \\
\hline Aromatics fraction $\%$ & 30.6 & 25.2 & 29.4 & 25.0 & 4309 & 33.2 & 39.3 & 29.0 & 37.4 & 36.04 & 3404 \\
\hline Saturates fraction $\%$ & 10.2 & 20.2 & 19.6 & 25.0 & 14.6 & 17.04 & 19.9 & 24.0 & 18.7 & 17.9 & 17.7 \\
\hline
\end{tabular}

\section{PROPERTIES OF ASPHALTS RECOVERED FROM OLD MIXTURES AND RECYCLED MIXTURES}

Physical and chemical properties of asphalts in mixtures change during heating, mixing and construction, further gradual changes occur also after construction. The asphalt recovered from old mixtures exhibits low penetration and high.

The asphalts recovered from recycled mixtures made by the Rejuvenating Method have a higher penetration index than those

from the conventional mixture and the recycled mixtures made by the Blending Method. This commonly connected with a tendency among results of four fractions to separate. For example, there is a correlation between penetration index and weight percent of asphalt's fraction. It therefore nay be said that the asphalts in the recycled mixtures made by the rejuvenating Method had not been rejuvenated completely.

\section{PROPERTIES OF RECYCLED MIXTURES}

\section{1- Compatibility}

Properties of asphalt mixtures are dependent on their compaction. So, compatibility is very important for recycled mixtures. Because recycled mixtures contain an old hardened asphalt it may be anticipated that the recycled mixture will exhibit workability than the conventional Mixture. But, the old hardened asphalt had adhered to the aggregate before the mixture was made. This may contribute to enhancing compatibility. The experimental results that the maximum densities of the two recycled mixtures are higher than that of the conventional mixture and the temperature for producing the maximum density falls with addition of the recycling agent.

\section{2- Softening point}

The penetration index tends to be a little higher than that of the new asphalt. The rheological characterization of asphalt can be controlled by addition of an appropriate recycling agent, and will be considerably influences by its chemical composition. Test results of asphalts recovered from the 11 asphalt mixture samples are listed in Table (6).

\section{3- Mixture Stiffness}

It is generally said that stiffness of recycled mixtures is higher than that of conventional mixtures. The high stiffness may be caused by high viscosity of the asphalt binders and high density of the mixtures. The experimental results show that the mixture stiffness for the recycled mixtures is higher than that of the conventional mixture at the same binder stiffness. The difference is caused by difference in densitiesTable (6).

\section{4- Resistance to Fatigue Cracking}

It is well known that the resistance to fatigue cracking of asphalt mixtures has a close relationship to the corresponding stiffness. Stiffness' of recycled mixtures are generally higher than the conventional mixtures. So, there is concern about the possibility of fatigue cracking in the recycled mixtures. we carried out research on relationships between fatigue life and dissipated energy [5]. These were measured in repeated bending tests under controlled strain conditions. Though there is some scatter, a straight-line relation can be obtained for each mixture sample.

\section{5-Water Resistance}

The stability of asphalt mixtures decrease with progression of stripping in the mixtures. The stripping phenomenon is recognized as the displacement of binder from the surface of the aggregate caused by the combined action of water and traffic loading. The stripping rate depend on the amount of deformation by the traffic load adhesion of the binder to the aggregate, permeability of the mixture, viscosity and moveability of the asphalt binder, and the like [6].

Recycled asphalt mixtures have high resistance to deformation, high adhesion and high viscosity of the stripping. In order to evaluate water-resistance of the recycled asphalt mixture, immersion wheel tracking tests were carried out. Specimens are deformed by the action of wheel- tracking. The resistance to stripping of 
mixtures can be evaluated by comparing the relations between stripping ratio and surface deformation [7].

Results of the tests indicate that the resistance to stripping of the recycled mixtures is better than that of the conventional mixture.

\section{ASPHALT MIXTURES CHARACTERISTICS}

Elasticity moduli have been computed using a regression model, which has been based on a wide range of asphalt mixes ranging from asphalt concrete to sand asphalt mixes. This mode allows for the generation of moduli-temperature relationships from month to month during the year. It is as follow [8]:

$$
\begin{aligned}
& \log (E)=1.430-0.0233\left(P_{\text {air }}\right)+0.013\left(P_{19}\right)+0.063(n) \\
& -0.008(T)+0.146 \log (f)+0.0000193(f)\left(T^{2}\right) \\
& -0.000073\left(T^{2}\right)-0.00014\left(V_{\text {eff }}\right)\left(P_{4}\right)+0.0058\left(P_{200}\right)\left(V_{\text {abs }}\right)
\end{aligned}
$$

Where:

$\mathrm{E}=$ Elastic modulus of asphalt mix, psi $(0.014 \mathrm{kPa})$

$\mathrm{P}_{\text {air }}=$ Percent air voids

$\mathrm{P}_{19}=$ Percent aggregate retained on sieve size $19 \mathrm{~mm}$

(3/4 inch), by dry aggregate weight

$\mathrm{n}=$ Asphalt cement viscosity at $70^{\circ} \mathrm{F}\left(1.8^{\circ} \mathrm{C}+32\right)$

$\mathrm{f}=$ Load frequency, $\mathrm{Hz}$

$\mathrm{V}_{\text {eff }}=$ Effective volume of asphalt cement, percent

$\mathrm{P}_{4}=$ Percent aggregate retained on sieve No. 4

$P_{200}=$ Percent aggregate passing sieve No. 200

$\mathrm{V}_{\mathrm{abs}}=$ percent absorbed asphalt by volume

General Characteristics of different asphalt mixes are

\begin{tabular}{|c|c|c|c|c|c|c|c|c|}
\hline $\begin{array}{c}\text { Virgin Aggrregat } \\
\%\end{array}$ & \multicolumn{2}{|c|}{5} & \multicolumn{2}{|c|}{15} & \multicolumn{2}{|c|}{25} & \multicolumn{2}{|c|}{35} \\
\hline Add Rejuvenate & Yes & No & Yes & No & Yes & No & Yes & No \\
\hline Air Voids \% & 5.6 & 7.6 & 8.0 & 7.7 & 6.5 & 6.0 & 6.2 & 7.4 \\
\hline Ret. No. $19 \%$ & 2.0 & 2.0 & 2.0 & 2.0 & 2.0 & 2.0 & 2.0 & 2.0 \\
\hline Visc., M Poise & 3.1 & 3.1 & 3.1 & 3.1 & 3.1 & 3.1 & 3.1 & 3.1 \\
\hline $\begin{array}{l}\text { Eff. Asphalt } \\
\text { Volume (\%) }\end{array}$ & 12.5 & 11.4 & 12.0 & 11.6 & 12.3 & 12.2 & 12.2 & 11.5 \\
\hline Ret. No. 4 (\%) & 37.0 & 37.0 & 37.0 & 37.0 & 37.0 & 37.0 & 37.0 & 37.0 \\
\hline Pass No. $200(\%)$ & 5.0 & 5.0 & 5.0 & 5.0 & 5.0 & 5.0 & 5.0 & 5.0 \\
\hline $\begin{array}{l}\text { Abs. Asphalt by } \\
\text { Volume (\%) }\end{array}$ & 0.47 & 1.4 & 0.75 & 1.3 & 0.7 & 0.72 & 0.84 & 1.4 \\
\hline
\end{tabular}
given in Table (6).

Table (6) Properties of Recycled Asphalt Mixes.

Conclusions

This research project evaluated the performance of recycled asphalt pavement (RAP) by Superpave method. The results may be concluded as follows:
1- Asphalt's in the old mixtures used for recycling have low penetration and high softening point. Moreover, their penetration indices tend to be higher than those of the new asphalt's that is their temperature susceptibility is lower.

2- It seems that asphalt's in the recycled mixtures made by the Rejuvenating Method have not been rejuvenated completely.

3- Density of the recycled mixtures is higher than that of the conventional mixture and their stiffness' are higher.

4- Fatigue life of the recycled mixtures is longer than that of the conventional mixture.

5 -Water-resistance evaluated by the immersion wheel tracking test also is better.

6- RAP can be combined (in both high and low percentages) in Superpave mixes. In general, the variation of RAP percentage used in a mix has no significant effect on the moisturesusceptibility of the mixtures.

\section{References}

1- Epps, J.A., D.N. Little, and R.J. Holmgreen, "Guidelines for Recycling Pavement Materials," NCHRP Report No. 224, Transportation Research Board, Washington, D.C., September 1980.

2- Brown, D., "Recycling Practices for HMA," Special Report No. 187, National Asphalt Pavement Association, Lanham, MD, September 2000, pp. 7-9.

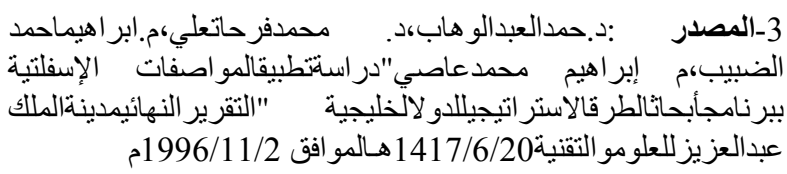

4-Mise, T., Yamada, M. and To Kodak, H. Recycled asphalt mixed with new performs better than new alone, Highway public Words, 48,1846,18-24,1980.

5- Yamada, M. Resistance to deformation of asphalt paving mixtures under repeated loading, proc. of Japan cong. Materials Res. 27,181-186,1984.

6- Mise, T., Yamada, M. and Negoro, H. Stripping phenomenon in the asphalt paving mixture, Memoirs of Faculty of Eng., Osaka City Univ., 139-150,1982.

7- Mise, T,. Yamada M. and Negoro, H. Astudy of stripping in asphalt mitures by immersion wheel tracking test, Memoirs of Fiche Hy of Eng., Osaka City Univ., 21,213-221,1980.

8- EPPS, J.A., Little, D.N. and Holmgreen, R.J., "Guidelines for Recycling Pavement Materials", NCHRP Report 224, September, 1980 